\title{
NASA TECHNICAL STANDARDS PROGRAM \\ AND \\ IMPLICATIONS FOR LESSONS LEARNED \\ AND TECHNICAL STANDARD INTEGRATION
}

\author{
Paul S. Gill and Danny Garcia \\ NASA Technical Standards Program Office \\ William W. Vaughan \\ University of Alabama in Huntsville
}

\section{Background}

The National Aeronautics and Space Agency consists of fourteen Facilities throughout the United States. They are organized to support the Agency's principal Enterprises: (1) Space Science, (2) Earth Science, (3) Aerospace Technology, (4) Human Exploration and Development of Space, and (5) Biological and Physical Research. Technical Standards are important to the activities of each Enterprise and have been an integral part in the development and operation of NASA Programs and Projects since the Agency was established in 1959. However, for years each Center was responsible for its own standards development and selection of non-NASA technical standards that met the needs of Programs and Projects for which they were responsible. There were few "Agencywide" applicable Technical Standards, mainly those in area of safety. Department of Defense Standards and Specifications were the foundation and main source for Technical Standards used by the Agency. (Figure 1) This process existed until about 1997 when NASA embarked on a Program to convert NASA's Center-developed Technical Standards into Agencywide endorsed NASA Preferred Technical Standards. In addition, action was taken regarding the formal adoption of non-NASA Technical Standards (DOD, SAE, ASTM, ASME, IEEE, etc.) as NASA Preferred Technical Standards.

\section{BACKGROUND AND CONTEXT}

Traditionally, NASA "Technical Standards" were built around specific programs and organizations, e.g.,

- Apollo, Shuttle, Space Station, Explorers...

- NASA Field Centers - MSFC, JSC,...

- Liberal use was made of MIL-STD's. Agencywide Technical Standards were generally limited to specific areas:

- Safety, Mission Assurance, Electronic Components

- Construction of Facilities

- Data Communications Standards

- Technical Standards were prescriptive and essentially "good forever"

- Establishment and use of an Agencywide Technical Standards Program has been established and accepted.

FIGURE 1 
Technical Standards are important to the Agency for many reasons. For example, they are used in contract proposal reviews to verify inputs, in-house design and development activities, support contractor use, to capture lessons learned and new technology, and to maintain engineering excellence in research and development and operations. They provide a common base for interoperability.

\section{GOALS, AUTHORITY, AND DELEGATION OF AUTHORITY}

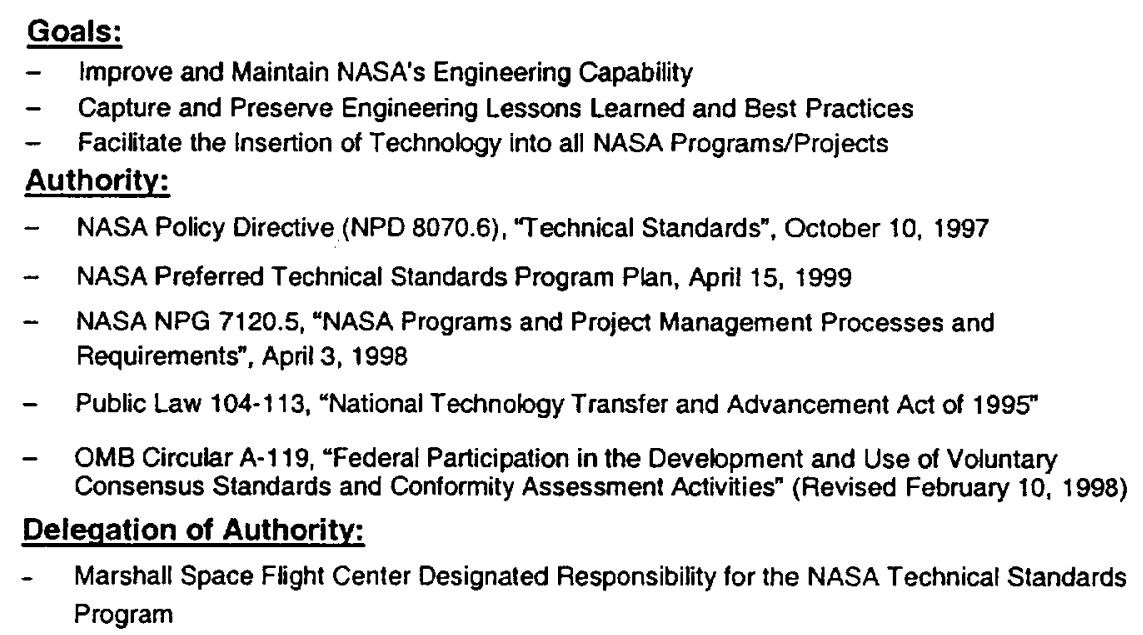

\section{FIGURE 2}

The NASA Technical Standards Program has three major goals: (1) Improve and Maintain NASA's Engineering Capability, (2) Capture and Preserve Engineering lessons Learned and Best Practices, and (3) Facilitate the Insertion of Technology into all NASA Programs and Projects. It functions under the authority of a Directive issued by the NASA Administrator in 1999 and within the scope of Public Law 104-113 and OMB Circular A-119. The NASA Marshall Space Flight Center was assigned responsibility for the Program and as Agency Lead to work with the other NASA Facilities in that role. The NASA Technical Standards Program functions under the purview of the NASA Chief Engineer on the Administrators Staff (Figure 2)

The Technical Standard Program has several key elements. They include the development of NASAunique Technical Standards; formal adoption of non-NASA Technical Standards, especially those developed by Voluntary Consensus Standards Developing Organizations; conversion of NASA's Centerdeveloped Technical Standards and, of considerable importance to the Agency's Programs and Projects, the development of NASA's Integrated Technical Standards Initiative. This is a unique Initiative not duplicated within Government or Industry, and resulted from interactions with many Managers and staff members of NASA Programs and Projects, plus individual engineering and scientific staff member of the Centers. The three focal point of the Initiative consist of the Agencywide Full-text Technical Standards System, Standards Update Notification. System, and the Lessons Learned/Best Practices/Application Notes-Standards Integration System. All of these Systems have been implemented. Their further development and enhancement to meet the Agency's engineering needs continues as experience and feedbacks are obtained from the users. (Figure 3) 


\section{Program Elements}

- NASA-Unique Standards Development

- Conversion of Center-Developed Standards to NASA Preferred Technical Standards (NASA or Non-Government)

- Voluntary Consensus Standards (Non-Government) Adoption and Development

- Standardization Awareness

- NASA Integrated Technical Standards Initiative

- Agencywide Full-text Technical Standards System

- Standards Update Notification System

- Lessons Learned/Best Practices/Application Notes Standards Integration System

\section{FIGURE 3}

The Lessons Learned/Best Practices/Application Notes-Standards Integration System has become one of the significant thrusts of the Program. It evolved from interactions with engineering and scientific staff members involved in the definition, design, development, and operation of space flight systems. The initial effort has involved the linking of the NASA Lessons Learned Information System database entries to the NASA Preferred Technical Standards. In addition, a search for other aerospace related databases, document, etc. produced over 120 sources that have been noted on the Program's Website. They are currently being screened for integration with NASA Preferred Technical Standards. (Figure 4)

\section{Lessons Learned/Best Practices/Application Notes - Standards Integration System}

- Standards are a Natural Focus for Lessons Learned

- Standards are the Tools Used by Engineers

- Integrating Lessons Learned With Standards Provides Basis for Their Interpretation/Use and Update of Standards

- Current Status

- "Application Notes" Linked to Over 160 "Preferred" Technical Standards

- 176 Lessons Learned from LLIS Linked to 72 NASA Preferred Technical Standards

- Standards Website Currently Contains Additional 120 Lessons Learned Database/Site Links within NASA

- Over 1700 Access to These Databases

- More Than 200 Accesses to NASA'S Lesson's Learned Information-System

FIGURE 4 


\section{Lessons Learned-Standards Integration}

\section{(a) Lessons Learned.}

The use of lessons learned is a principal component of any organizational culture committed to continuous improvement. They have formed the foundation for discoveries, inventions, improvement, textbooks, AND technical standards. Technical standards are a very logical way to communicate these lessons. Using the time-honored tradition of passing on lessons learned while utilizing the newest in information technology, the National Aeronautics and Space Administration (NASA) has launched an intensive effort to link lessons learned with specific technical standards through various Internet databases. This article will discuss the importance of lessons learned and best practices, the difficulty in finding relevant lessons learned while engaged in an engineering project, and the new NASA project that can help alleviate this difficulty. The article will conclude with recommendations for more expanded cross-sect oral uses of lessons learned with reference to technical standards.

In the technical arena, truly useful lessons learned must be significant in that they have a real or assumed impact on operations, valid in that they are technically correct, and applicable in that they address a specific design process or decision that mitigates or eliminates the risk for failures or reinforces a positive result. They should communicate only lessons, and should not be used as a replacement for other management information functions such as self-assessment, failure investigation, and corrective action systems.

Lessons learned are a powerful method of sharing ideas for improving work processes, facility or component design and operation, quality, safety, and cost effectiveness. Properly implemented, they should improve management decision-making during every phase of a project's development and operation.

It is important to document lessons learned in order to convey information on experiences, to control recurrence of a problem, improve safety, enhance risk management, and facilitate improved interoperability. Thus, they are an important and critical resource that can be used by engineers, scientists, and technicians to support, for example, the design of flight and ground support hardware, software, facilities, and procedures. Sometimes best practices are also referred to as lessons learned applied.

Information on lessons learned may be found in a number of different locations, including organizational technical reports, professional engineering journals, and databases specifically focused on lessons learned. But locating a lesson learned applicable to one's specific interest is generally not a very "user friendly" experience--hence the motivation for developing a "marriage" with technical standards.

(b) The Problem

With the explosion in technical accomplishments during the past century, especially during the last few decades, it has become critical to rapidly communicate the knowledge gained through experience. This is very true for activities associated with producing more advanced products within the "faster, better, cheaper" philosophy. The dependence upon word of mouth and textbooks to communicate lessons learned, while-still important, is no longer adequate or realistic. Expecting engineers and scientists to search through the ever-increasing number and contents of lessons learned databases has proven to be less than productive. It is difficult and time consuming for most engineers to search for and use such lessons learned databases. However, there is a viable solution to this problem. 


\section{(c) A Solution}

All NASA Programs and Projects are based on the application of technical standards, whether produced by government agencies including the Department of Defense, or by non-government standards developing organizations. The development of these and other technical standards have gone through an extensive review process. Given this database of technical standards, along with the existence of a screened lessons learned database, a productive marriage of the two is now possible.

Currently the NASA Technical Standards Program Web site has incorporated over 120 national and international lessons learned databases since June 2001, providing engineers and other interested parties a chance to find the relevant experiences of other professionals who have already encountered specific concerns in aerospace engineering.

To view these, go to http://standards.nasa.gov and then click the NASA ACESS or Public ACESS links on the menu page. Once registered, click on the Lessons Learned/Best Practices link for direct access to the listing of lessons learned databases related to aerospace engineering.

Here are some examples of lessons learned databases incorporated into the NASA Technical Standards Program Web site.

NASA/Headquarters--Lessons Learned Information System;

NASA/Glenn Research Center--Frequently Asked Questions On Failures;

NASA/Goddard Space Flight Center--Systems Engineering Office Lessons Learned;

Satellite Mission Operations Best Practices; and

NASA/Langley Research Center--Lessons for Software Systems.

(d) The Approach

On the surface, this marriage appears easily achievable but this is not the case. It requires the talents of dedicated and experienced engineers who must also possess the gifts of persistence and meticulous attention to detail. The material involved must be read and interpreted and then correlated. The lessons learned database must then be integrated with the technical standards database. Both databases continue to grow at a prolific rate. Once related, the lessons learned must be reviewed and associated with the applicable technical standards.

A NASA "pilot" effort to test this approach has been successful. Consideration is being given to expand the effort beyond the NASA Preferred Technical Standards database. To the degree practical, this should be done in collaboration with the standards developing organizations involved.

The result will be an invaluable database whereby any technical standard required for a program or project design, development, or operations process will also have identified with it any relevant lessons learned. This marriage will without doubt significantly encourage the development of "faster, better, cheaper" products. Also, technical standards with associated lessons learned may be candidates for revision or may spur the development of a new technical standard.

\section{(e) Example}

To illustrate the results of the pilot effort regarding the integration of information on lessons learned with technical standards, an example is presented as it appears within the NASA Technical Standards Program Web site. This example is taken from the Agencywide Full-Text Technical Standards System within the NASA Access site on the main menu page. (Unfortunately, due to licensing agreements on the access to 
non-government technical standards products, the NASA Access site is only available to those within the nasa.gov domain.)

Figure 5 provides an illustration of the Standards Document Summary page for MIL-STD-1686 C, Electrostatic Discharge Control Program for Protection of Electrical and Electronic Parts, Assemblies, and Equipment (Excluding Electrically Initiated Explosive Devices), a NASA Preferred Technical Standard. The information provided for a user on this NASA Preferred Technical Standard includes two lessons learned links, plus a brief description of each, that are available on the NASA Lessons Learned Information System (LLIS) database. The user of this standard can then easily locate the two listed lessons learned through hyperlinks and decide whether the contents might be applicable to their use of this MIL-STD. The full-text content of this ML-STD is readily available from both the NASA ACCESS and Public ACCESS sites.

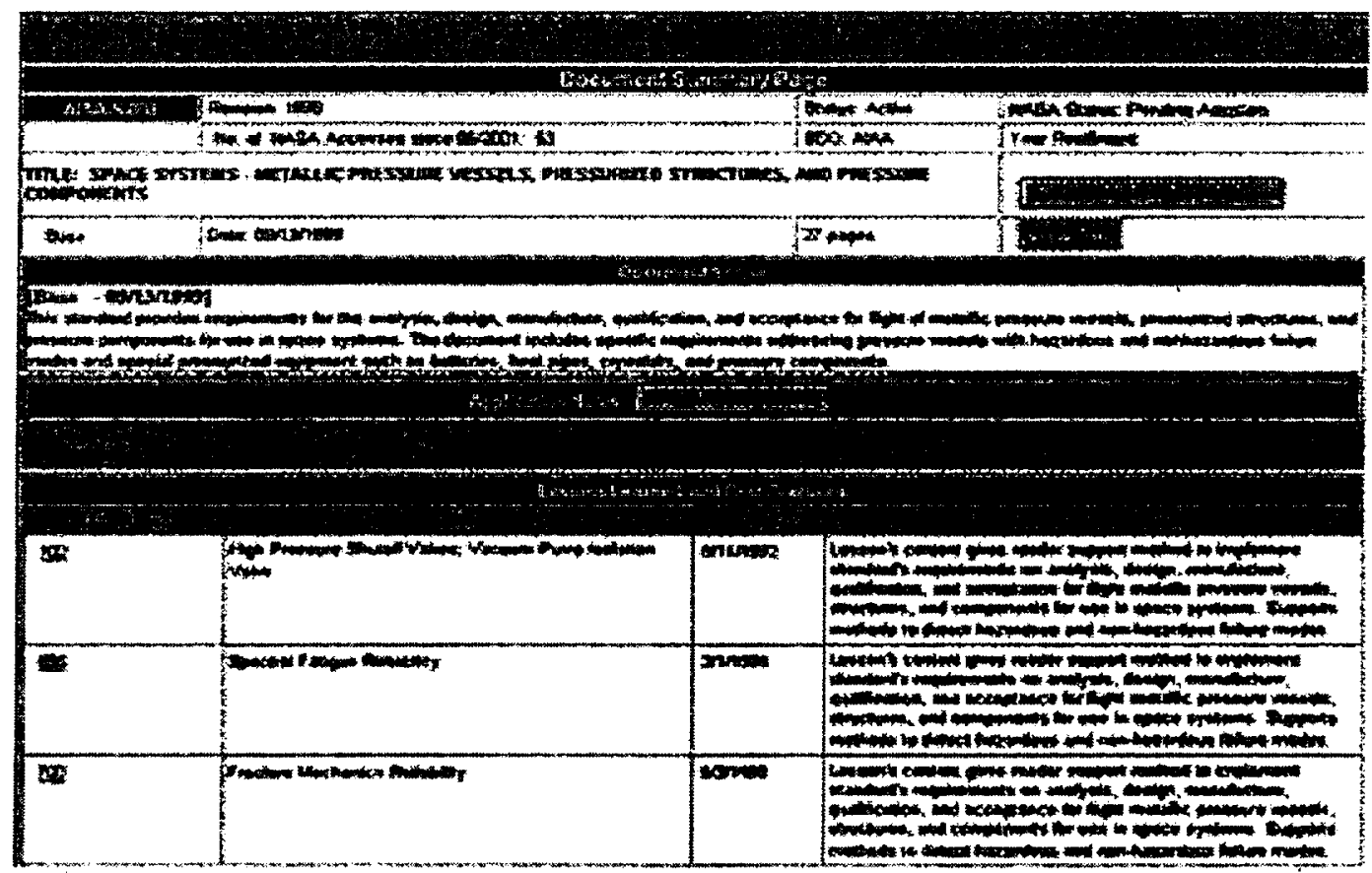

FIGURE 5

(The contents of this section are excerpts from the paper "Lessons Learned and Technical Standard: A Logical marriage" by the authors and published in the November 2001 issue of ASTM Standardization News.)

\section{Space Operations}

An appropriate example of Lessons Learned/Best Practices can be found in the "Satellite Mission Operations Best Practices" document prepared by the Best Practices Working Group of he AIAA's Space Operations and Support Technical Committee (SOSTC). It is posted on the SOSTC's Website at the following address:

\section{http://www.aiaa.org/tc/sos/bpintro.htm}

(The contents of this section are excerpts from this document and based on the information therein) 
The Satellite Mission Operations Best Practices document continues to be enhanced by contributions to its contents from members of the Best Practices Working Group and others associated with the Group. There are ten topics completed with other "in the works":

Configuration Management

Training and Certification

Process Improvement

Ground Systems Development

Pre-launch Spacecraft Operations Development and Test

Launch and Early Operations

Flight Dynamics

Off-Line Spacecraft Performance Assessments

Multi-Mission Satellite Operations Center

Operations Cost Containment-Elements of Low Cost Approach

Operations Management

Real-Time Control Operation

Mission Planning and Scheduling

Contingency Planning and Support

The contents of this document are recommendations and rules of thumb; not declarations of what you "shall do". These are NOT Standards and have not gone through the years of review often required of a Standard. They are based on the real world experiences of people working in Satellite Mission Operations. They are Lessons Leaned-Applied. This database reflects one of the many the NASA Technical Standards Program has selected for further screening and efforts to integrate into its NASA Preferred Technical Standards as appropriate relative to the topics (Best Practices) identified.

\section{Summary Remarks}

In the Space Operations arena, links should be established as soon as practical between lessons learned and, where possible, the technical standards to which they relate. This can be accomplished by government organizations such as NASA and DOD, industry groups, and standards developing organizations. The results can then be made available and shared with all interested parties. Users of the technical standards would then have immediate links, access to lessons learned and other relevant information as they select and apply technical standards in the normal design, development, and operations process.

The longer-term goal should be to update technical standards, where appropriate, to reflect lessons learned. Normal practice in the standards community is for technical standards to be reviewed and, where necessary, updated at least once in five years. Links to related lessons learned would provide a basis for additions and updates of technical standards, thus facilitating the marriage process. For government and non-government developed technical standards, the addition of lessons learned can be made directly whenever prudent. To accomplish this goal, and thus reduce mission risk, it is recommended that initiatives by those developing and using technical standards products be established to integrate lessons learned with technical standards.

The existence of integrated lessons learned and technical standards system will certainly contribute toward minimizing Space Operation risks. Only one project saved or enhanced will repay the cost of developing an integrated lessons learned and technical standards system many-fold. Without this marriage the lessons learned and best practices database, and other similar databases, will continue to find limited and very focused utility relative to the development and operation of future industry and government programs and projects. 
NASA Technical Standards Program Website Homepage (Figure 6)

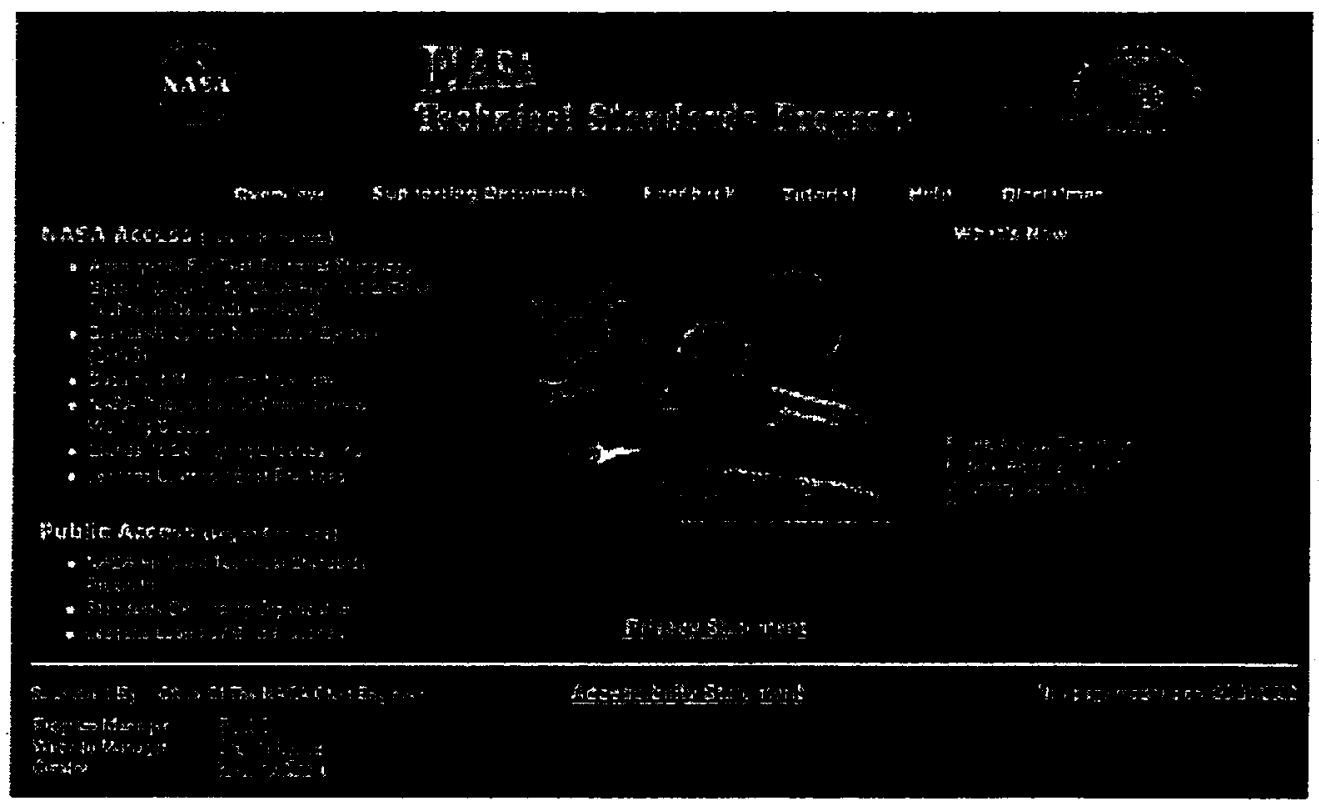

FIGURE 6

$\overline{\text { END }}$

Prepared June 21, 2002, for presentation at:

SpaceOps 2002 Conference

In Association With The World Space Congress 2002

October 10-19, 2002

Houston, Texas 